\title{
Protein-Losing Enteropathy after the Fontan Operation
}

\author{
Fernando Tadeu Vasconcelos Amaral e Edmar Atik \\ Hospital das Clínicas da Faculdade de Medicina de Ribeirão Preto - USP and Instituto do Coração do Hospital das Clínicas - FMUSP \\ Ribeirão Preto, SP - São Paulo, SP - Brazil
}

In 1971, Fontan and Baudet were the first to describe a surgical technique for the successful separation of the systemic and pulmonary circulations in a patient with tricuspid atresia ${ }^{1}$. Soon after, Kreutzer suggested a similar procedure for a patient with the same condition ${ }^{2}$. This innovative procedure became known as "the Fontan operation", which, especially in the 1970's and 1980's, provided a better prognosis for patients with functionally univentricular hearts. Since these early impressive reports, several modifications of the techniques have been described as an attempt to further improve the function of both circulations $s^{3-5}$.

In the past twenty years, the short-term outcome of this procedure has improved significantly ${ }^{6,7}$, basically due to better patient selection, progress in surgical techniques and to more adequate immediate postoperative intensive care. However, as time went by and a new group of patients survived, sequelae of Fontan-like operation became apparent, making it less attractive. Hence, complications such as arrhythmias ${ }^{8,9}$, poorer physical fitness ${ }^{10}$, circulatory failure ${ }^{11,12}$, atrial thrombosis ${ }^{13,14}$ and liver dysfunction ${ }^{15}$ are frequent in the follow-up of these patients at outpatients' clinics and require special care and appropriate management.

A rare complication, although potentially lethal, is the protein-losing enteropathy (PLE) with pathogenesis and treatment still under discussion. The aim of this study is to review the clinical features of patients with PLE, to discuss the reported pathogenic mechanisms and to summarize the published therapeutic options that are potentially applicable to these patients.

\section{Diagnosis}

Patients with PLE present with bloating or abdominal pain, diarrhea, edema, pleural effusion, ascites and distress. Laboratory findings usually include hypoproteinemia, low serum immunoglobulins and calcium levels and low lymphocyte count. The onset of EPP may occur from weeks to years after the surgical procedure. In a study by Mertens ${ }^{16}$, this interval ranged from one month to 16 years (mean: 2.7 years). The diagnosis of PLE is confirmed by finding high fecal $\alpha 1$-antitrypsin levels in patients with no other causes of hypoalbuminemia, such as liver disease or malnutrition ${ }^{17-19}$. Associated infections may occur due to immune dysfunction confirmed by the low lymphocyte count and immunoglobulin levels ${ }^{20}$. Some cases may present with no diarrhea and with slight hypoalbuminemia, despite the marked reduction in serum immunoglobulin levels and lymphocyte counts, especially of $\mathrm{CD}^{21}{ }^{21}$. According to some authors, transaminases may be increased due to secondary liver congestion ${ }^{22}$.

\section{Key words}

Operation, Fontan, protein loss.
Subclinical gastrintestinal protein loss may occur with no evidence of the classical clinical findings and with normal serum protein levels ${ }^{23}$.

\section{Incidence}

As far as is known, PLE was first described in 1960 in a 17-year old patient with constrictive pericarditis ${ }^{24}$. Hypoalbuminemia, hypocalcemia and steatorrhea markedly improved after surgery. After this report, others were published describing patients with similar findings secondary to chronic constrictive pericarditis ${ }^{25}$, tricuspid insufficiency ${ }^{26}$, Mustard operation $^{27}$ and Glenn operation ${ }^{28}$.

The incidence of PLE after Fontan operation is variable and was first described by Crupi, in $1980^{29}$. Shortly after the report of three patients operated by Hess $^{30}$, Driscol demonstrated that $10 \%$ of 352 cases operated on before 1985 had PLE. This study highlighted the importance of some variables associated with PLE and became an important reference for the Fontan operation ${ }^{12}$. The incidence of PLE following the Fontan operation has been reported as 2.5 to $10 \%^{23,31-34}$, but always in studies involving a small number of patients. In a large multicenter study published in 1998 and involving 3,029 patients, PLE was diagnosed in 114 cases (3.7\%). This study is a landmark in PLE characterization and demonstrated, among other relevant aspects, the low incidence of this syndrome in patients who underwent the Fontan operation.

\section{Pathogenesis}

The mechanisms involved in triggering PLE have been under debate for almost 50 years. As early as 1961, Davidson ${ }^{25}$ associated the occurrence of the syndrome with high venous pressure and consequent changes in the intestinal lymphatics. Chylous dilatation of small bowel villi ${ }^{35}$ could cause local edema with secondary protein loss. Curiously, Blalock, in $1936^{36}$, induced this physiological change by occluding the superior vena cava of dogs, and caused obstruction of flow in the thoracic ducts and congestion of the intestinal lymphatics. These early studies clearly depicted the role of the small bowel in protein loss, supposedly related to increased central venous pressure. This seemingly obvious concept was challenged by Wilkinson in $1965^{37}$, who was the first researcher to perform jejunal biopsy in a patient with PLE and normal venous pressure, demonstrating the characteristic lymphangiectasis. Another important feature described by Strober, in $1968^{26}$, was fecal lymphocyte and protein loss, potentially reversible by treating the heart disease ${ }^{38}$.

In 1984, Hess $^{30}$ reported three cases of PLE after surgical atriopulmonary connection. These patients had high right atrial diastolic pressure; since anterograde flow in the superior vena cava after the Fontan operation takes place during atrial 


\section{Clinical Update}

diastole, PLE was allegedly associated to this physiologic variable.

Recent studies have reported cases of protein loss in a circumscribed intestinal region. In 1999, Koch ${ }^{21}$ employed Tc99-labeled albumin and demonstrated a marked reduction in CD4+ lymphocytes of unknown origin in patients with circumscribed intestinal protein loss. According to this author, passive lymph loss secondary to high central venous pressure could not explain the selective loss of CD4+ lymphocytes, suggesting that the primary or secondary disturbance of the immune system could affect the structural integrity and patency of the intestinal wall, thus triggering PLE. In theory, if proven, the circumscribed loss would have definite surgical consequences in these patients. An interesting aspect, recently reported is the possible association of increased mesenteric vascular resistance with $\mathrm{PLE}^{39}$. These authors suggested that the increased resistance would cause mesenteric hypoperfusion, which would be a possible substrate for the development of the syndrome.

\section{Treatment}

The five-year survival rate of patients with PLE after the Fontan operation ranges between $46 \%$ and $59 \%{ }^{16,31}$. Such figures point out to the extreme severity of this complication, and support the efforts made to optimize the treatments available.

\section{Medical Treatment}

in addition to the use of anti-congestive medications, such as diuretics and ACE inhibitors, the replacement by periodic infusion of albumin, immunoglobulins and lymphocytes should be done. Also, patients must be advised to ingest hyperproteic and medium-chain-triglyceride rich diets. In 2003, Chakrabarti ${ }^{20}$ considered that perhaps these patients had acquired immunodeficiency due to fecal lymphocyte loss and recommended the prophylactic use of antibiotics and the prompt treatment of any infection. Antiviral vaccines and immunoglobulin replacement are also recommended and aim to improve the immunological protection of these patients ${ }^{40}$. Some specific measures have been used with different success rates:

a) Steroids: following Silverman's ${ }^{41}$ report on the treatment of intestinal lymphangiectasis, Rothman ${ }^{42}$, in 1991, used prednisone to treat a patient with PLE diagnosed two years after the Fontan operation, with no signs of circuit obstruction and with a mean pressure of $10 \mathrm{mmHg}$ in the right atrium. This innovative experience was soon reproduced with satisfactory result ${ }^{43,44}$ despite the small number of patients. Zellers' experiment was rather interesting, for it clearly demonstrated, though in a single patient, the association between use of steroids and anatomical changes in the duodenal biopsy. With the use of $2 \mathrm{mg} / \mathrm{kg} /$ day in the first intervention, an improved clinical picture was evident. However, relapse occurred when the drug was discontinued and novel improvement occurred by reintroducing it at $0.5 \mathrm{mg} / \mathrm{kg} /$ day. In this case, it was then demonstrated the association of high fecal $\alpha 1$-antitrypsin and hypoalbuminemia with dilated intestinal villi in the biopsy. It is believed that in addition to its anti-inflammatory effect, steroids may be stabilizing factors of lymphatic and capillary membranes and may reduce the bulk of lymphatic tissue ${ }^{45}$.

Although representing an interesting therapeutic option, the use of steroids is not widely accepted. In the impressive multicenter trial reported by Mertens ${ }^{16}, 52$ patients received single medical treatment with a death rate of $46 \%$. In 16 patients who used prednisone the syndrome resolved in 5, improved in 7 and did not change in 4, thus demonstrating that the drug may be effective. Despite some unfavorable outcomes with this drug reported by other authors, there is evidence of good response in patients with no obstruction in the Fontan circulation. Therefore, this therapeutic option will seem reasonable until prospective studies are carried out. It is worth mentioning that the patient with PLE may be immunesuppressed due to fecal lymphocyte loss; worsening may occur if steroids are used.

b) Heparin: curiously, the mother of a patient with congenital heart disease and PLE observed that the child's diarrhea improved when warfarin was replaced by heparin whenever the child needed surgery. In 1997, Donelly ${ }^{46}$ reported the successful use of heparin in lower doses than those usually employed in anticoagulation in three patients with PLE. Heparin sulfate is a component of the basal membrane of several organs. When removed from other membranes but preserving proteoglycans, there is a considerable increase in membrane permeability to proteins ${ }^{47}$. The use of exogenous heparin, particularly high molecular weight heparin, may stabilize interactions in the capillary endothelium and the intestinal mucosa, with a consequent decrease in protein loss. In addition, heparin may enhance perivascular protein reabsorption into the lymphatic system.

c) Calcium: in 2004, $\mathrm{Kim}^{48}$ prescribed calcium alone, with no steroids or heparin, to a child with PLE, abiding to the patient family's desire. The child improved within four weeks, taking a turn for the worse soon after the drug was discontinued and again improving when reinitiated.

d) Spironolactone: Ringel ${ }^{49}$, in one sole experience, reported the use of spironolactone in three patients with PLE, with considerable improvement.

\section{Percutaneous intervention}

In 1994, Mertens ${ }^{50}$ reported the case of a 29-year old patient with refractory PLE after atriopulmonary anastomosis, who responded to percutaneous fenestration in the interatrial septum region. This procedure, even though successful, may be difficult to carry out due to the presence of Goretex or complex baffle in the intra-atrial conduit. Despite its attractiveness, this procedure should not be routinely used, since it was tested in only a few cases. Novel techniques are being tested in some centers and may shortly be included in the therapeutic armamentarium ${ }^{51}$. It is noteworthy mentioning that in Mertens ${ }^{\prime}$ trial $^{16}$, carried out in 1998, 13 patients underwent heart catheterization, three of them with associated surgical treatment. Nine patients underwent dilation with balloon catheter with or without stent placement; in that, three to relieve circuit obstruction and six to dilate pulmonary artery obstruction. Eight out of these nine cases had technically successful outcomes, five of whom with improvement of pulmonary obstruction and three with no clinical improvement. Five patients underwent atrial fenestration by means of blade septostomy, three with dilation by balloon catheter, one with interatrial septum puncture and dilation and one with stent placement. Three patients improved significantly while two, only partially. Two patients had stroke and one of them was not on anticoagulants. Other single case studies have been recently reported, such as the azygos vein embolization with Gianturco coil in PLE patients 
after the Glenn operation ${ }^{52}$. It is believed that the vein-vein shunt interruption was accountable for the PLE improvement in this case. It is important to highlight at this point that these summarized interventionist options may be of help in treating PLE due to the obstruction of Fontan circulation while, at the same time, they demonstrate the limited efficacy of the interatrial fenestration.

\section{Pacemaker Implantation}

An interesting report by Cohen ${ }^{53}$ was published in 2001 regarding this procedure. In two patients with PLE after the Fontan operation and associated sinus node dysfunction, the implantation of a pacemaker increased cardiac output and resolved the syndrome. After this, pacemaker implantation was considered a possible intervention to treat PLE, even in patients with no arrhythmias.

\section{Surgical Treatment}

From the early trials in cases of constrictive pericarditis ${ }^{24,25}$, tricuspid insufficiency ${ }^{26}$ and the Mustard operation with vena cava obstruction ${ }^{27}$, cardiovascular surgery has been an option for treating PLE. In 1980, $\mathrm{Crupi}^{29}$ described the supposedly first case successfully treated by surgery for PLE after the Fontan operation. The insertion of a biological valve in the proximal anastomosis in a patient with previously performed atriopulmonary connection with a valveless conduit and marked regurgitation resulted in great improvement, normalizing the serum protein levels. Fifty-two patients with PLE of the multicenter Mertens trial ${ }^{16}$, in 1998, underwent surgery with high mortality rate (61\%); among the survivors, $19 \%$ still had signs of PLE. Different surgical procedures aiming to optimize the Fontan-like circulation were employed, such as conduit disobstruction, valvuloplasty and septal defects occlusion. Conversion to other types of anastomosis was performed in a small number of patients and the most common was the conversion of atriopulmonary anastomosis into total cavopulmonary connection. Other interventions, including the undoing of the Fontan operation and heart transplantation were carried out in a small number of patients.

It is speculated that delay in surgery and irreversibility of enteric damage, even after postoperative hemodynamic improvement, may be factors of surgical failure. One must also consider that conversion into another Fontan-like circulation may not prevent PLE. Another option is the surgical atrial fenestration, described in $1996^{54}$. In this interesting study, two cases of PLE refractory to medical treatment had an excellent outcome after a $4.8 \mathrm{~mm}$ surgical atrial fenestration. It is noteworthy, as mentioned by other authors, that patients become cyanotic after this intervention, with risk of embolism. In 1997, Rychik ${ }^{55}$ described five patients who underwent lateral tunnel Fontan operation, and had PLE in the followup. When treated with surgical atrial fenestration, in three of them protein levels normalized and PLE symptoms subsided two to six weeks after the procedure. In the two patients who did not improve, blood $\mathrm{O}_{2}$ saturation was grater than $89 \%$ and the authors suggested that the clinical improvement seems to be related to the degree of right-left shunt created by the fenestration, and blood $\mathrm{O}_{2}$ saturation should not be grater than $85 \%$.

In 1998, Barbero-Marcial et al ${ }^{56}$ described an interesting surgical technique in patients with PLE after atriopulmonary anastomosis. In all three cases, conversion into cavopulmonary anastomosis and diversion of the hepatic veins to the left atrium were performed. Despite technically cumbersome, it seems to be a useful choice, as long as all hepatic veins are excluded from the venous system avoiding that any remaining vein facilitate the communication between the vena cava and the portal system, thus increasing the risk of cyanosis.

Thirty-one patients reoperated after the Fontan procedure were recently reported by Marceletti et al ${ }^{34}$, most of them due to arrhythmia and heart failure. Three of these patients had PLE, two of whom improved after extracardiac insertion of a polytetrafluoroethylene (PTFE) valveless tube connecting the inferior vena cava to the right pulmonary artery, associated to the reduction of the right atrium. Twenty-seven of the 31 patients are classified as functional class I or II, which confers to this type of anastomosis a hemodynamic efficiency superior to other techniques ${ }^{57}$.

Despite the small cumulative experience, heart transplantation may be an alternative, sometimes the only one, for treating $\mathrm{PLE}^{58,59}$. Brancaccio et $\mathrm{al}^{60}$ reported one interesting case of heart transplantation in a patient with PLE. As PLE persisted after such radical surgery, total parenteral nutrition was initiated with improvement after 16 weeks.

Connor ${ }^{61}$ has recently described the innovative experience of a 14-year old female patient with PLE refractory toboth medication of any type and the Fontan operation revision. The affected small bowel area was localized by means of TC99-dextran scintigraphy. After resection of $135 \mathrm{~cm}$ of the jejunum, the PLE gradually improved, despite the demonstration of persisting protein loss on a new scintigraphy. In spite of the successful results of this procedure in patients with PLE and intestinal lymphangiectasis ${ }^{62}$, its benefits to patients after the Fontan operation, as well as the incidence of circumscribed lesions have still to be determined. What would be the determining factor of the enteric lesion in a specific site? What would be the long-term results of cases operated with this technique? Could other lesions appear in different areas of the small bowel after successful resection? These practical questions will remain unanswered until larger studies are performed.

\section{Prevention}

The cumulative analysis of patients undergoing the Fontan operation enabled the recognition of some variables possibly related to the worsening of PLE and, thus, the early identification of possible patients at risk. At this point, the classical work by Driscol ${ }^{12}$, in 1992, should be mentioned. This author verified that patients with heterotaxia, polysplenia, systemic venous drainage anomalies, high pulmonary vascular resistance and high left ventricular diastolic pressure had a significantly greater chance of developing PLE after the Fontan operation. These findings were later confirmed, in 1996, by Feldt ${ }^{31}$, who added that right ventricular anatomy, as well as the duration of extracorporeal circulation and of hospitalization were also significantly associated with the appearance of the syndrome. In 2001, Powell ${ }^{63}$ reported 416 patients who underwent the Fontan operation: 103 (12.6\%) cases submitted to extracorporeal circulation for over 140 minutes had PLE, whereas only $313(0.6 \%)$ with extracorporeal circulation lasting less than 140 minutes presented PLE $(p<0.001)$.

This information is relevant for the selection of surgical candidates, as well as for choosing the operative technique to be used. For instance, could patients at risk of developing PLE benefit from atrial fenestration during the Fontan operation? 


\section{Clinical Update}

One should also consider the possibility of patients with subclinical PLE ${ }^{23}$, who have definite protein loss but not the typical findings of the syndrome, and who deserve closer attention. As suggested by Fuji64, in 2003, the fecal protein loss precedes hypoproteinemia. One wonders whether these patients would have a better outcome if treated before the appearance of the full-blown syndrome.

Recent data indicate that the immune system has an important role in the genesis of PLE. Patients with low lymphocyte count, especially CD4+ and CD5, seem prone to $\mathrm{PLE}^{65}$. Shimilu et al ${ }^{66}$ have recently shown that increased interferon gamma in the intestinal mucosa leads to protein loss not accompanied by epithelial changes under electronic microscopy. Agreeing with Chakrabarti, in $2003^{20}$, the information above indicates that determining the immunological profile of the operated patient seems to be important. Prophylactic treatments in patients with immune dysfunction may influence the onset of PLE. The postoperative size of the right atrium may be related to the appearance of $\mathrm{PLE}^{35}$.

\section{Conclusion}

Based on the review above, PLE after Fontan operation is a well-known disorder of low incidence but of poor prognosis. Its diagnosis should be suspected in any patient undergoing the Fontan operation and presenting diarrhea and hypoproteinemia with or without edema. Subclinical PLE is well recognized, but its role in the outcome of these patients is

\section{References}

1. Fontan F, Baudet E. Surgical repair of tricuspid atresia. Thorax 1971; 6: 240-8.

2. Kreutzer G, Galindez E, Bono H, de Palma C, Laura JP. An operation for correction of tricuspid atresia. J Thorac Cardiovasc Surg 1973; 66: 61321.

3. Yacoub MH, Radley-Smith R. Use of a valved conduit from right atrium to pulmonary artery for "correction" of single ventricle. Circulation 1976; 54 (suppl 3): 63-70.

4. Gale AW, Danielson GK, McGoon DC, Mair DD. Modified Fontan operation for univentricular heart and complicated congenital lesions. J Thorac Cardiovasc Surg 1979; 78: 831-8.

5. Marceletti C, Mazzera E, Olthof H,et al. Fontan's operation. An expanded horizon. J Thorac Cardiovasc Surg 1980; 80: 764-9.

6. Mair DD, Hagler DJ, Julsrud PR, Puga FJ, Schaff HV, Danielson GK. Early and late results of the modified Fontan procedure for double-inlet left ventricle: the Mayo Clinic experience. J Am Coll Cardiol 1991; 18: 1727-32.

7. Mayer Jr JE, Bridges ND, Lock JE, Hanley FL, Jonas RA, Castaneda AR. Factors associated with marked reduction in mortality for Fontan operations in patients with single ventricle. J Thorac Cardiovasc Surg 1992; 103: 444-51.

8. Weber HS, Hellenbrand WE, Kleinman CS, Perlmutter RA, Rosenfeld LE. Predictors of rhythm disturbances and subsequent mortality after the Fontan operation. Am J Cardiol 1989; 64: 762-7.

9. Fishberger SB, Wernowsky G, Gentles TL, et al. Factors influencing the development of atrial flutter after the Fontan operation. J Thorac Cardiovasc Surg 1997; 113: 80-6.

10. Driscoll DJ, Danielson GK, Puga FJ, Schaff HV, Heise CT, Staats BA. Exercise tolerance and cardiorespiratory response to exercise after the Fontan operation for tricuspid atresia or functional single ventricle. J Am Coll Cardiol 1986; 7: 1087-94.

11. Fontan F, Kirklin JW, Fernandez G, et al. Outcome after a "perfect" Fontan operation. Circulation 1990; 81: 1520-36.

12. Driscoll DJ, Offord KP, Feldt RH, Schaff HV, Puga FJ, Danielson GK. Five to still unknown. Localized obstructions should be sought, as they may cause the syndrome. However, PLE with no obstructions is quite frequent and its pathogenesis is possibly related to complex immune mechanisms. It is mandatory to diagnose acquired immunodeficiency in these patients. Regarding treatment, the patients with circulatory obstruction should be appropriately managed to avoid venous hypertension. The treatment of causes not related to obstruction is still open to debate. Steroids, although not universally accepted, may be used with attention given to possible worsening of an already existing immunodeficiency. Heparin and spironolactone may be useful, although their benefits are yet to be proven. Percutaneous intervention has specific indications, but is not always effective. Surgical optimization of the Fontanlike circulation must be considered whenever possible. Surgical atrial fenestration, conversion into cavopulmonary anastomosis and heart transplantation may be indicated in specific cases. It is important to choose the ideal candidate for the Fontan operation, as PLE seems to be less frequent in certain functional and anatomical circumstances.

Despite its grim prognosis, the recent interest in the elucidation of the mechanisms involved in the syndrome is fundamental to find the ideal treatment. Even though the Fontan operation is a widely practiced procedure in Brazil, few papers were written on PLE pointing to the need of a multicenter Brazilian trial. Such a trial is important to assess the magnitude of the problem, the characteristics of Brazilian patients and the therapeutic options available.

fifteen-year follow-up after the Fontan operation. Circulation 1992; 85: 469-96.

13. Dobell ARC, Trusler GA, Smallhorn JF, Williams WG. Atrial thrombi after the Fontan operation. Ann Thorac Surg 1986; 42: 664-7.

14. Mahony L, Nikaidoh H, Fixler DE. Thrombolytic treatment with streptokinase for late intraatrial thrombosis after modified Fontan procedure. Am J Cardiol 1988; 62: 343-4.

15. Cromme-Dijkhuis AH, Hess J, Hahlen K, et al. Specific sequelae after Fontan operation at mid-and long-term follow-up. Arrhythmia, liver dysfunction and coagulation disorders. J Thorac Cardiovasc Surg 1993; 106: 1126-32.

16. Mertens L, Hagler DJ, Sauer U, Somerville J, Gewillig M (On behalf of the PLE study group). Protein-losing enteropathy after the Fontan operation: an international multicenter study. J Thorac Cardiovasc Surg 1998; 115: 1063-73.

17. Mulberg AE, Piccoli DA, Murphy J, Norwood WI. Severe enteric protein loss causes hypoproteinemia and hypogammaglobulinemia following the modified Fontan procedure (Abstract). Circulation 1989; 80 (suppl II): II489.

18. Hill DJ, Feldt RH, Porter CJ, Puga FJ, Danielson GK, Perrault J. Proteinlosing enteropathy after Fontan operation: a preliminary report (Abstract). Circulation 1989; 80 (suppl II): II-490.

19. Florent C, L'Hirondel C, Desmazures C, Aymes C, Bernier JJ. Intestinal clearance of alpha-1-antitrypsin: a sensitive method for the detection of protein-losing enteropathy. Gastroenterology 1981; 81: 777-80.

20. Chakrabarti S, Keeton BR, Salmon AP, Vettukattil JJ. Acquired combined immunodeficiency associated with protein losing enteropathy complicating Fontan operation. Heart 2003; 89: 1130-1.

21. Koch A, Hofbeck M, Feistel H, Buheitel G, Singer H. Circumscribed intestinal protein loss with deficiency in CD4+ lymphocytes after the Fontan procedure. Eur J Pediatr 1999; 158: 847-50.

22. Gentles TL, Gauvreau K, Mayer Jr JE, et al. Functional outcome after the Fontan operation: factors influencing late morbidity. J Thorac Cardiovasc 
Surg 1997; 114: 392-403.

23. Thorne SA, Hooper J, Somerville J. Gastrointestinal protein loss in long term survivors of the Fontan operation. B Heart J 1995; 73 (suppl 3) (Abstract).

24. Jiménez-Diaz G, Linazosoro JM, López-Garcia E, Ramirez-Guedes J. Sobre la hipoalbuminemia en la pericarditis: mecanismo y repercusiones: estúdios com proteínas marcadas de la rapidez de perdida y renovación de la albumina del plasma. Rev Clin Espan 1960; 77: 252-6.

25. Davidson JD, Waldman TA, Goodman DS, Gordon RS. Protein-losing gastroenteropathy in congestive heart failure. The Lancet $1961 ; 1$ : 8999-2.

26. Strober W, Cohen LS, Waldmann TA, Braunwald E. Tricuspid regurgitation. A newly recognized cause of protein-losing enteropathy, lymphocytopenia and immunologic deficiency. Am J Med 1968; 44: 842-50.

27. Moodie DS, Feldt RH, Wallace RB. Transient protein-losing enteropathy secondary to elevated caval pressures and caval obstruction after the Mustard procedure. J Thorac Cardiovasc Surg 1976; 72: 379-82.

28. Gleason WA, Roodman ST, Laks H. Protein-losing enteropathy and intestinal lymphangiectasia after superior vena cava-right pulmonary artery (Glenn) shunt. J Thorac Cardiovasc Surg 1979; 77: 843-6.

29. Crupi G, Locatelli G, Tiraboschi R, Villani M, De Tommasi M, Parenzan L. Protein-losing enteropathy after Fontan operation for tricuspid atresia (imperforate tricuspid valve). Thorac Cardiovasc Surg 1980: 28: 359-63.

30. Hess J, Kruizinga K, Bijleveld CMA, Hardjowijono R, Eyegelaar A. Proteinlosing enteropathy after Fontan operation. J Thorac Cardiovasc Surg 1984; 88: 606-9.

31. Feldt RH, Driscoll DJ, Offord KP, et al. Protein-losing enteropathy after the Fontan operation. J Thorac Cardiovasc Surg 1996; 112: 672-80.

32. Kaulitz R, Luhmer I, Bergmann F, Rodeck B, Hausdorf G. Sequelae after modified Fontan operation: postoperative haemodynamic data and organ function. Heart 1997; 78: 154-9.

33. Mair DD, Puga FJ, Danielson GK. The Fontan procedure for tricuspid atresia: early and late results of a 25-year experience with 216 patients. J Am Coll Cardiol 2001; 37: 933-9.

34. Marcelletti CF, Hanley FL, Mavroudis C, et al. Revision of previous Fontan connections to total extracardiac cavopulmonary anastomosis: a multicenter experience. J Thorac Cardiovasc Surg 2000; 119: 340-6.

35. Gordon RS Jr. Exudative enteropathy: abnormal permeability of the gastrointestinal tract demonstrable with labelled polyvinylpyrrolidone. Lancet 1959; 1(7068):325-6.

36. Blalock SA, Cunningham RS, Robinson CS. Experimental production of chylotorax by occlusion of superior vena cava. Ann Surg 1936; 104: 35964.

37. Wilkinson P, Pinto B, Senior JR. Reversible protein-losing enteropathy with intestinal lymphangiectasia secondary to chronic constrictive pericarditis. The N Eng J Med 1965; 273: 1178-81.

38. Nelson DL, Blaese RM, Strober W, Bruce RM, Waldmann TA. Constrictive pericarditis, intestinal lymphangiectasia, and reversible immunologic deficiency. J Ped 1975; 86: 548-54

39. Rychik J, Gui-Yang S. Relation of mesenteric vascular resistance after Fontan operation and protein-losing enteropathy. Am J Cardiol 2002; 90: 672-4.

40. De Giocoso C, Maggiore G, Scotta MS. Admnistration of intravenous immunoglobulin in two children with hypogammaglobulinemia due to protein losing enteropathy. Clin Exp Immunol 1985; 60: 447-8.

41. Silverman A, Roy CC. Protein-losing enteropathy. In: Silverman A, Roy CC, (eds.) Pediatric clinical gastroenterology. 3rd ed. St. Louis: The CV Mosby Co.; 1983: 304-23.

42. Rothman A, Snyder J. Protein-losing enteropathy following the Fontan operation: resolution with prednisone therapy. Am Heart J 1991; 121: $618-9$.

43. Rychik J, Piccoli DA, Barber G. Usefulness of corticosteroid therapy for protein-losing enteropathy after the Fontan procedure. Am J Cardiol 1991; 68: 819-21

44. Zellers TM, Brown K. Protein-losing enteropathy after the modified Fontan operation: oral prednisone treatment with biopsy and laboratory proved improvement. Pediatr Cardiol 1996; 17: 115-7.
45. McEvoy GK (ed.) American Hospital Formulary Service Drug Information Bethesda: American Society of Hospital Pharmacists; 1989: 1662

46. Donnelly JP, Rosenthal A, Castle VP, Holmes RD. Reversal of protein-losing enteropathy with heparin therapy in three patients with univentricular hearts and Fontan palliation. J Pediatr 1997; 130: 474-8.

47. KanwarYS, Linker A, Farquhar MG. Increased permeability of the glomerula basement membrane to ferritin after removal of glycosaminoglycans (heparin sulfate) by enzyme digestion. J Cell Biol 1980; 86: 688-93.

48. Kim SJ, Park IS, Song JY, Lee JY, Shim WS. Reversal of protein-losing enteropathy with calcium replacement in a patient after Fontan operation. Ann Thorac Surg 2004; 77: 1456-7

49. Ringel RE, Peddy SB. Effect of high-dose spironolactone on protein-losing enteropathy in patients with Fontan palliation of complex congenital hear disease. Am J Cardiol 2003; 91: 1031-2.

50. Mertens L, Dumoulin M, Gewillig M. Effect of percutaneous fenestration of the atrial septum on protein-losing enteropathy after the Fontan operation. Br Heart J 1994; 72: 591-2.

51. Rychik J. Management of protein-losing enteropathy after the Fontan procedure. Ped Cardiac Surg Ann Seminars in Thorac Cardiovasc Surg 1998; 1: 15-21

52. Ishii A, Fuse S, Kuno N, et al. Improvement of protein-losing enteropathy by coil embolization of the left azygos vein. Cathet Cardiovasc Interv 2003 59: 399-401.

53. Cohen MI, Rhodes LA, Wernovsky G, Gaynor W, Spray TL, Rychik J. Atria pacing: an alternative treatment for protein-losing enteropathy after the Fontan operation. J Thorac Cardiovasc Surg 2001; 121: 582-3.

54. Jacobs ML, Rychik J, Byrum CJ, Norwood Jr WI. Protein-losing enteropathy after Fontan operation: resolution after baffle fenestration. Ann Thorac Surg 1996; 61: 206-8.

55. Rychik J, Rome JJ, Jacobs ML. Late surgical fenestration for complications after the Fontan operation. Circulation 1997; 96: 33-6.

56. Barbero-Marcial M, Riso A, Atik E, et al. Cavo-pulmonary anastomosis excluding the portal venous return: an alternative for patients with proteinlosing enteropathy secondary to the Fontan procedure. Cardiol Young 1998; 8: $221-7$

57. Gellat M, Hamilton RM, McCrindle BW, et al. Risk factors for atria tachyarrhythmias after the Fontan operation. J Am Coll Cardiol 1994; 24: 1735-41.

58. Holmgren D, Berggren $\mathrm{H}$, Wahlander H, Hallberg M, Myrdal U. Reversal of protein-losing enteropathy in a child with Fontan circulation is correlated with central venous pressure after heart transplantation. Pediatr Transplant 2001; $5: 135-7$

59. Sierra C, Calleja F, Picazo B, Martinez-Valverde A. Protein-losing enteropathy secondary to Fontan procedure resolved after cardiac transplantation. J Pediatr Gastroenterol Nutr 1997; 24: 229-30.

60. Brancaccio G, Carotti A, D’argenio P, Michielon G, Parisi F. Protein-losing enteropathy after Fontan surgery: resolution after cardiac transplantation. ) Heart Lung Transplant 2003; 22: 484-6.

61. Connor FL, Angelides S, Gibson M, et al. Successful resection of localized intestinal lymphangiectasia post-Fontan: role of 99 mtechnetium-dextran scintigraphy. Pediatrics $2003 ; 112 ; 242-7$.

62. Persic M, Browse NL, Prpic I. Intestinal lymphangiectasia and protein losing enteropathy responding to small bowel resection. Arch Dis Child 1998; 78 194.

63. Powell AJ, Gauvreau K, Jenkins KJ, Blume ED, Mayer JE, Lock JE. Perioperative risk factors for development of protein-losing enteropathy following a Fontan procedure. Am J Cardiol 2001; 88: 1206-9.

64. Fujii T, Shimizu T, Takahashi K, et al. Fecal $\alpha 1$-antitrypsin concentrations as a measure of enteric protein loss after modified Fontan operations. J Pediat Gastroenterol Nutr 2003; 37: 577-80.

65. Lenz D, Hambsch J, Schneider P, et al. Protein-losing enteropathy in patients with Fontan circulation: is it triggered by infection? Critical Care 2003; 7: 185-90.

66. Shimizu T, Nagata S, Fujii T, etal. Enhanced production of interferon-gamm as a possible cause of protein-losing enteropathy after modified Fontan operation. J Pediatr Gastroenterol Nutr 2003; 37: 504-7. 